
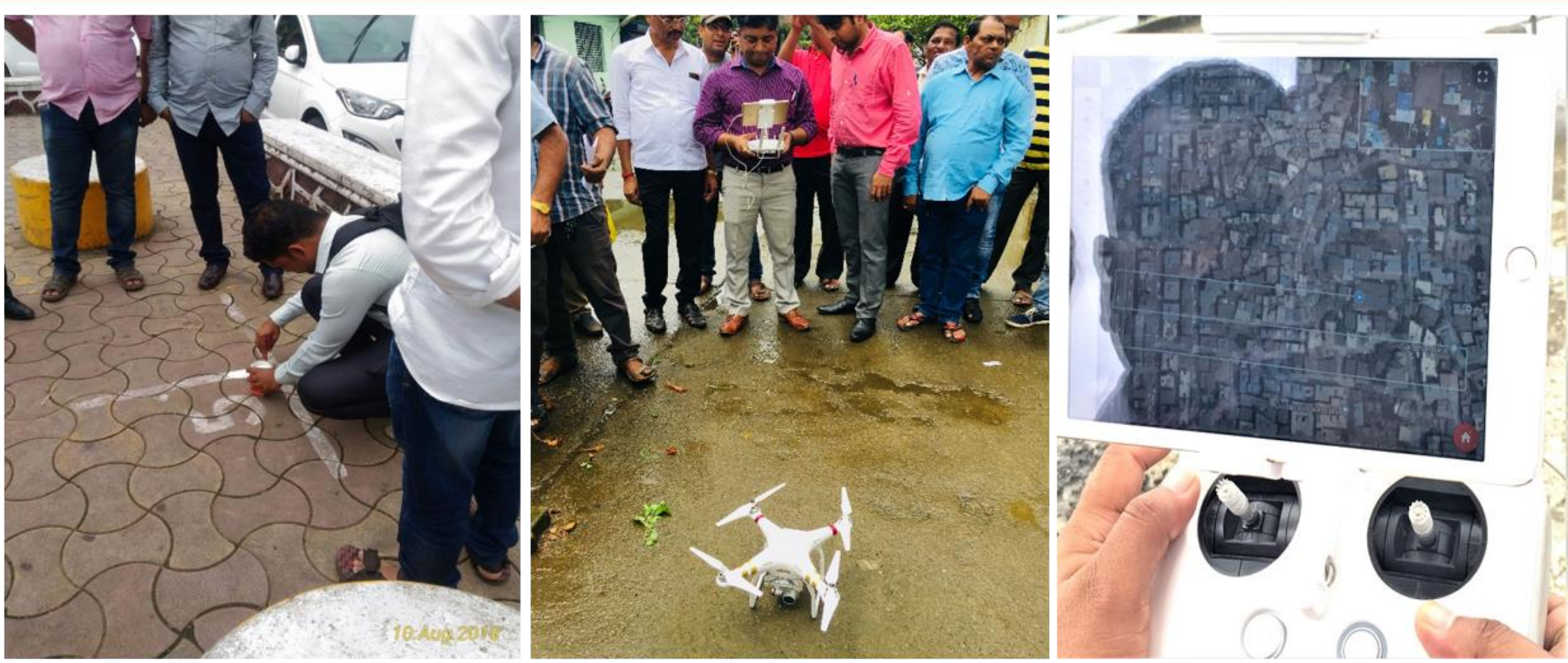

\title{
ANALYSING THE EFFICIENCY AND SUITABILITY OF DRONE TECHNOLOGY FOR CITY-SURVEYS IN MAHARASHTRA
}

Executive Summary

Since the launch of the National Land Records Modernisation Programme (NLRMP) by the Government of India (now the Digital India Land Records Modernisation Programme (DILRMP)) in August 2008, land and property records have been a part of important administrative discussions. As is the case with most of India, land records in Maharashtra are largely limited to agricultural areas, while built up or abadi areas, termed as 'gaothan' areas in rural Maharashtra have minimal property records. The Government of Maharashtra (GoM) has initiated surveys of gaothan areas (the statutory framework in Maharashtra refers to these as 'city surveys') using drone technology to map properties and establish accurate, up-to-date maps accompanying textual records.
This policy brief explores the level of efficiency and suitability of drone surveys for surveying gaothan areas.

Based on a study conducted by the Indian Institute for Human Settlements (IIHS) of the survey methodology adopted by the GoM, this policy brief discusses the applications of technology in surveys, analyses the limitations of drone surveys, and recommends a combination of survey techniques to assist state governments to conduct surveys of inhabited areas in more accurate and efficient ways. 


\section{Introduction}

Drone technology is considered an advanced survey technique to capture high resolution and accurate datasets. The high level of manoeuvrability makes it easy to update maps unlike in ground-based survey and gives easy accessibility to unapproachable areas using limited manpower.

However, the selection of survey methods must be based on the characteristics of the area and requirements of the project. It therefore, depends on a range of parameters like the extent of the survey area, the built-up density, vegetation cover, desired data accuracy, the budget and time frame available.

At present, the range of survey techniques available are:

a) Ground method using Electronic Total Station (ETS) and Differential Global Positioning System (DGPS)

b) Hybrid methodology using HighResolution Satellite Imagery (HRSI) and ground truthing by ETS and DGPS

c) Aerial photography/ drone (UAVUnmanned Aerial Vehicle) and ground truthing by ETS and DGPS

d) Light Detection and Ranging (LIDAR) iiand DGPS.

On visiting the sites during the surveys conducted by the GoM and documenting the survey process, a list of 'good practices' and 'gaps' of the survey process and the technology used was analysed.

\section{Existing status of property records in Maharashtra}

There are a total of 43,665 villages in Maharashtra, of which only around 3,800 have been surveyed since the process was first started during British rule.
In the absence of surveys, gaothan areas are usually left as composite large plots in the rural land records, and the details of the buildings or individual plots within the gaothan do not exist.

The villages that were surveyed earlier were done through ground surveys, which is a timeconsuming method to capture data, physically traverse the survey area and carry out ground verification. The high degree of human interventions in the survey process can lead to errors. On an average, a ground survey (such as an Electronic Total Station (ETS) survey) takes over three months of time to capture the data of a single village of approximately 300500 properties, and will cost around INR $3,00,000^{\mathrm{iii}}$. Given the sheer size of the unsurveyed area in Maharashtra-around 40,000 villages-conducting the survey quickly but with high data accuracy is a major challenge, one which cannot be solved by using ground survey techniques. According to estimates by the GoM, it would take three decades to survey all the un-surveyed village if ground survey techniques were to be used. iv

Drone technology with ground truthing by ETS and DGPS was thus selected as the survey method by the GoM, the Revenue Department, Settlement Commissioner \& Director of Land Records (SC \& DLR) with support from the Survey of Indiav.

\section{Conducting the drone survey: pilot project}

The city survey was conducted as per the Maharashtra Land Revenue (Village, Town and City Survey) Rules, 1969. In this exercise, two villages of varied characteristics were identified for the pilot project to check the technique's efficiency- Sonori and Vashi.

Based on the discussion with officials from the Revenue Department, GoM, the IIHS study divided the city survey into three major stages- pre-survey, survey and post-survey. 
The figure below illustrates the process that was carried out for conducting this city survey.

Figure 1: Methodology to conduct city- survey using drone technology:
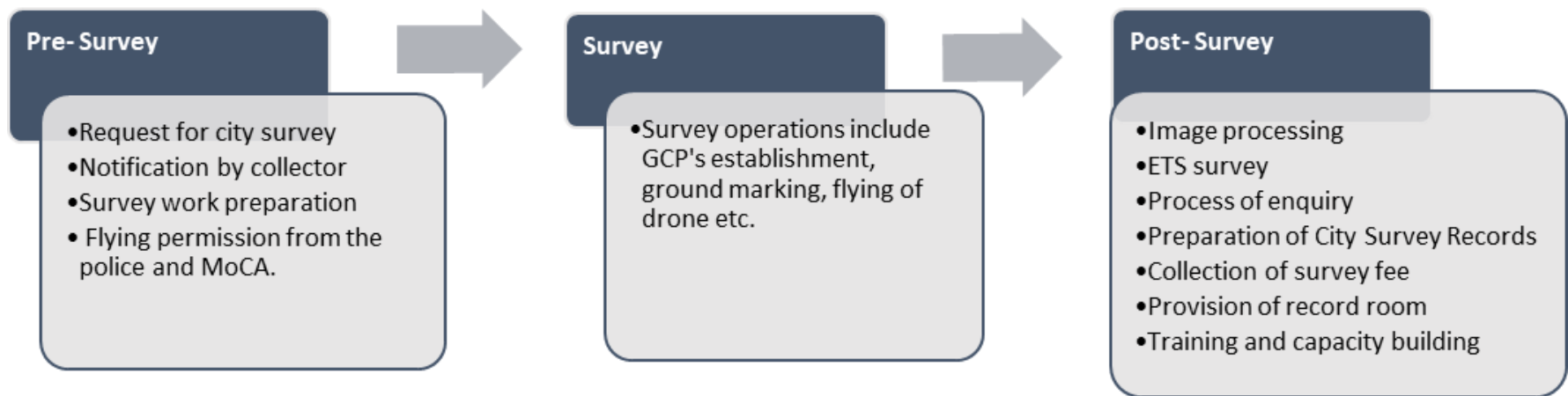

Source: IIHS analysis, based on field visits by IIHS during field surveys and discussion with officials from the Revenue Department, GoM

In pre- survey stage, the request for the city survey is generally put up either by local body (such as the village panchayat) or the rural development department to the SC \& DLR (Settlement Commissioner \& Director of Land Records), which is followed by final approval from District Collector (DC) and subsequent essential flying permissions from competent authorities.

The survey stage included on-ground preparation for the survey, such as ground marking and establishing Ground Control Points (GCPs), followed by the flying of the drone and data capturing.
During the survey, the gram sabha and villagers were involved in the identification and demarcation of government land, gram sabha land parcels, individual properties, roads, open plots etc. This practice helped to reduce property disputes.

The final stage included data processing, georeferencing and rectification of captured images, followed by ETS (if required), ground verification, inquiry proceedings and distribution of sanad. vi

\section{Key Findings}

It was found that in Sonori village, which is primarily a sparsely developed area, the drone was an effective and efficient technique but in the dense, heavily built up and more urbanised area of Vashi, the drone was not such an efficient technique as the dense built-up and vegetation covered area made it difficult for the drone to capture the building plinth. A further detailed list of findings were identified as 'good practices' or 'gaps': 


\begin{tabular}{|c|c|}
\hline Good practices & Gaps \\
\hline $\begin{array}{l}\text { - Using drone technology } \\
\text { was an advanced and } \\
\text { modern survey technique } \\
\text { to conduct the city survey. }\end{array}$ & $\begin{array}{l}\text { - In densely built-up areas or those with vegetation as in Vashi, the } \\
\text { plinth of the building was not visible from the drone lens, } \\
\text { reducing the accuracy of the image. As a result, a } 100 \text { percent } \\
\text { ground survey with ETS and ground truthing was necessary to } \\
\text { verify the data set and validate the data, which is as time } \\
\text { consuming as a pure ground survey. } \\
\text { - Drone surveys are subject to weather conditions and cannot be } \\
\text { conducted when visibility is poor, such as during rains, cloudy or } \\
\text { foggy weather. In the Navi Mumbai case, repeated survey } \\
\text { attempts due to weather constraints was time consuming. }\end{array}$ \\
\hline $\begin{array}{l}\text { DGPS was effectively used } \\
\text { to capture the Ground } \\
\text { Control Point (GCP) to geo- } \\
\text { reference the drone } \\
\text { images. }\end{array}$ & $\begin{array}{l}\text { - To achieve high accuracy and spatial resolution of image in } \\
\text { dense areas, a greater number of GCP and images were } \\
\text { required, increasing the time to collect and process the image. }\end{array}$ \\
\hline
\end{tabular}

\section{Recommendations}

- For densely built-up areas or those with vegetation, where the plinth of the buildings is difficult to detect through the drone lens, surveys can be done using LIDAR technology, which works on laser \& point cloud-based technique involving minimal human interventions and is not affected by poor weather conditions. For sparsely developed areas, drones can be recommended as an optimal, cost-effective and quick survey method for governments to conduct efficient property surveys.

\footnotetext{
'The GoM considers conducting city-surveys in gaothan areas (residential areas of villages) once the population in these areas crosses a threshold of 2000.

ii LIDAR technology works on laser \& point cloud-based technique. It is a combination of 3D spatial and spectral information to give high resolution and accurate images. iii Based on field visits by IIHS during field surveys and discussion with officials from the Revenue Department, GoM.
}

- This strategy of parallel survey can be quick, efficient and accurate.

- Use of LIDAR for one gaothan at time would be very expensive. LIDAR survey costs can be mediated by listing a sufficient number of appropriate densely built-up or vegetation covered pockets, and conducting the survey at one go rather than a piecemeal manner.

\footnotetext{
iv Nambiar N (2018, Dec 10). Government to clear drone survey of land for 4000 villages. The Times of India (Pune). $\checkmark$ The national survey and mapping organisation of the country under the Department of Science \& Technology, Government of India.

vi Sanad refers to authority given in writing by the government to hold land/ property. It includes name of owner, address, property area, dimensions and scaled layout of property.
} 